\title{
High dose intravenous vitamin $C$ treatment in Sepsis: associations with acute kidney injury and mortality
}

Thomas R. McCune ${ }^{1 *} \mathbb{D}$, Angela J. Toepp ${ }^{2,3}$, Brynn E. Sheehan²,4 Muhammad Shaheer K. Sherani ${ }^{5}$, Stephen T. Petr ${ }^{5}$ and Sunita Dodani ${ }^{2,6}$

\begin{abstract}
Background: The effects of vitamin C on clinical outcomes in critically ill patients remain controversial due to inconclusive studies. This retrospective observational cohort study evaluated the effects of vitamin $C$ therapy on acute kidney injury (AKI) and mortality among septic patients.

Methods: Electronic medical records of 1390 patients from an academic hospital who were categorized as Treatment (received at least one dose of $1.5 \mathrm{~g} \mathrm{IV}$ vitamin $C, n=212$ ) or Comparison (received no, or less than $1.5 \mathrm{~g} \mathrm{IV}$ vitamin $C, n=1178$ ) were reviewed. Propensity score matching was conducted to balance a number of covariates between groups. Multivariate logistic regressions were conducted predicting AKI and in-hospital mortality among the full sample and a sub-sample of patients seen in the ICU.
\end{abstract}

Results: Data revealed that vitamin C therapy was associated with increases in AKI (OR $=2.0795 \% \mathrm{Cl}[1.46-2.93])$ and in-hospital mortality $(\mathrm{OR}=1.6795 \% \mathrm{Cl}[1.003-2.78])$ after adjusting for demographic and clinical covariates. When stratified to examine ICU patients, vitamin C therapy remained a significant risk factor of AKI $(O R=1.6195 \% \mathrm{Cl}$ [1.09-2.39]) and provided no protective benefit against mortality ( $\mathrm{OR}=0.7995 \% \mathrm{Cl}[0.48-1.31])$.

Conclusion: Ongoing use of high dose vitamin C in sepsis should be appraised due to observed associations with AKI and death.

Keywords: Vitamin C therapy, Sepsis, Acute kidney injury, In-hospital mortality

\section{Clinical summary}

- Existing research regarding the effect of vitamin $C$ on outcomes in patients with sepsis is inconsistent.

- This retrospective study of patients hospitalized for sepsis revealed an association between IV vitamin C usage and subsequent AKI and in-hospital mortality.
- The relationship between early treatment of high dose IV vitamin $\mathrm{C}$ and mortality in septic patients might suggest potential nephrotoxicity of vitamin $\mathrm{C}$ therapy.

- Findings, coupled with results from multiple randomized controlled prospective studies of IV vitamin $C$ with mixed results, suggests that wide-spread use of high dose IV vitamin $\mathrm{C}$ requires further assessment.

\footnotetext{
*Correspondence: mccunetr@evms.edu

1 Division of Nephrology, Department of Internal Medicine, Eastern

Virginia Medical School, 301 Riverview Ave, Suite 600, Norfolk, Virginia

23510, USA

Full list of author information is available at the end of the article
}

(C) The Author(s) 2021. Open Access This article is licensed under a Creative Commons Attribution 4.0 International License, which permits use, sharing, adaptation, distribution and reproduction in any medium or format, as long as you give appropriate credit to the original author(s) and the source, provide a link to the Creative Commons licence, and indicate if changes were made. The images or other third party material in this article are included in the article's Creative Commons licence, unless indicated otherwise in a credit line to the material. If material is not included in the article's Creative Commons licence and your intended use is not permitted by statutory regulation or exceeds the permitted use, you will need to obtain permission directly from the copyright holder. To view a copy of this licence, visit http://creativecommons.org/licenses/by/4.0/. The Creative Commons Public Domain Dedication waiver (http://creativeco mmons.org/publicdomain/zero/1.0/) applies to the data made available in this article, unless otherwise stated in a credit line to the data. 


\section{Background}

The benefits of ascorbic acid (vitamin C) therapy were first noted in the 1970s, related to infections and the common cold [1]. The unique set of physiological properties of vitamin $C$ have given its use promise in decelerating a multitude of different forms of infection. Vitamin $\mathrm{C}$ serves to protect host cells from oxidative damage during the inflammatory response through its role as an antioxidant [2], it preserves other endogenous antioxidants, including lipid soluble vitamin $\mathrm{E}$ and glutathione [3], and it has been shown to contribute to bactericidal activity via augmentation of T-cell and neutrophil function [4]. As plasma vitamin $\mathrm{C}$ is quickly depleted during severe inflammatory states, vitamin $C$ has emerged as a possible adjuvant therapy in sepsis $[5,6]$.

Sepsis remains a major public health issue as the 10th leading cause of death among non-Hispanic black individuals and 12th among non-Hispanic white individuals in the U.S., and infecting more than 1.7 million U.S. Americans annually [7, 8]. Within the hospital setting, sepsis remains a significant concern with mortality rates above $50 \%$ and over $\$ 24$ billion dollars spent each year on sepsis-related hospitalizations [9-13]. Identifying effective and appropriate treatments to reduce sepsis-related mortality and hospital length of stay (LOS) remains a challenge.

Early examinations of vitamin $\mathrm{C}$ supplementation, alone or in combination with thiamine (vitamin B1) and corticosteroids, revealed decreased inflammatory markers and end-organ dysfunction [14, 15]. Extant research, however, is inconsistent regarding the effect of vitamin $C$ on outcomes in patients with sepsis. Of six randomized controlled trials, only two found improvement in patient markers such as SOFA score, vasopressor requirement, and lactate levels [14, 16-20]. Only one study found reduced likelihood of mortality with vitamin $C$ therapy; however, notably, this study did not find improvement in SOFA score [17]. Observational studies also remain mixed. One of three retrospective and quasi-experimental studies found improvements in both mortality and markers of patient stability, a second found a reduction in mortality but no benefit for markers of stability, and a third found no benefit of mortality or markers of stability $[15,21,22]$.

Similarly, research assessing the role of high dose vitamin $C$ in causing or protected against acute kidney injury (AKI) is also conflicting and lacks validity. Several case reports have identified AKI and oxalate nephropathy in patients who received high doses of vitamin C [23-25]. Other research has suggested vitamin $C$ may have some level of protectiveness against AKI [15] while other research including the large clinical trial, VICTAS, found there was no harmful or beneficial relationship [26, 27].
Given the contradictory findings in both RCTs and observational studies, more research is needed to ascertain the effects of vitamin $C$ therapy among septic patients. In the current study, a retrospective analysis was conducted to investigate the relationship of intravenous (IV) vitamin C on AKI and mortality among patients with sepsis.

\section{Methods \\ Clinical order set}

In August 2016, a sepsis vitamin order set was formalized but not mandated in the hospital in which the study was completed. The decision to utilize the order set was up to the individual provider. The order panel included IV vitamin $C$ at a dose of $1.5 \mathrm{~g}$, administered every $6 \mathrm{~h}$ for a maximum of 16 doses; IV hydrocortisone $50 \mathrm{mg}$ every $6 \mathrm{~h}$ up to 28 doses; and IV thiamine $200 \mathrm{mg}$ every $12 \mathrm{~h}$ for 8 doses. In December 2018, melatonin $0.5 \mathrm{mg}$ at bedtime was added to the order set with no stop required. The order panel did not include diagnostic studies to determine the severity of sepsis nor did it include treatment option directions based on clinical parameters.

\section{Study design}

This retrospective cohort study (Fig. 1) was conducted at a tertiary care, academic hospital and was approved by the Eastern Virginia Medical School Institutional Review Board. Adult patients, age 18 through 89 years, with International Classification of Disease (ICD)-10 code for "sepsis", admitted between August 1, 2016 and December 31, 2018, were identified via electronic health records (EHR-Epic Systems Corporation, Verona, WI, USA). Inclusion criteria included (1) admission via the ED, (2) hospitalization for at least $48 \mathrm{~h}$, and (3) two serum creatinine assays $48 \mathrm{~h}$ apart. ED admission was required in order to capture patients with community acquired infections and limit those with sepsis after nosocomial infections, post-surgical sepsis, and transfer patients who may have missed the opportunity for early vitamin $C$ therapy. These factors have been identified as potential confounders of treatment effectiveness, as nosocomial infections may be more likely to be drug resistant and more difficult to treat [28]. Patients with admission glomerular filtration rates (GFR) less than $35 \mathrm{ml} / \mathrm{min}$ (measured by the Modification of Diet in Renal Disease (MDRD) formula [29]), an initial creatinine greater than $4.0 \mathrm{mg} / \mathrm{dL}$ (KDIGO Stage 3 disease), or a diagnosis of end stage kidney disease or prior kidney transplant were excluded from the study. This was done to allow for the temporal assessment of development of AKI and to prevent the inclusion of individuals with poor kidney function.

The following data were collected from the EHR: patient demographics; past medical history; visit characteristics (i.e., pre-identified medications administered, 


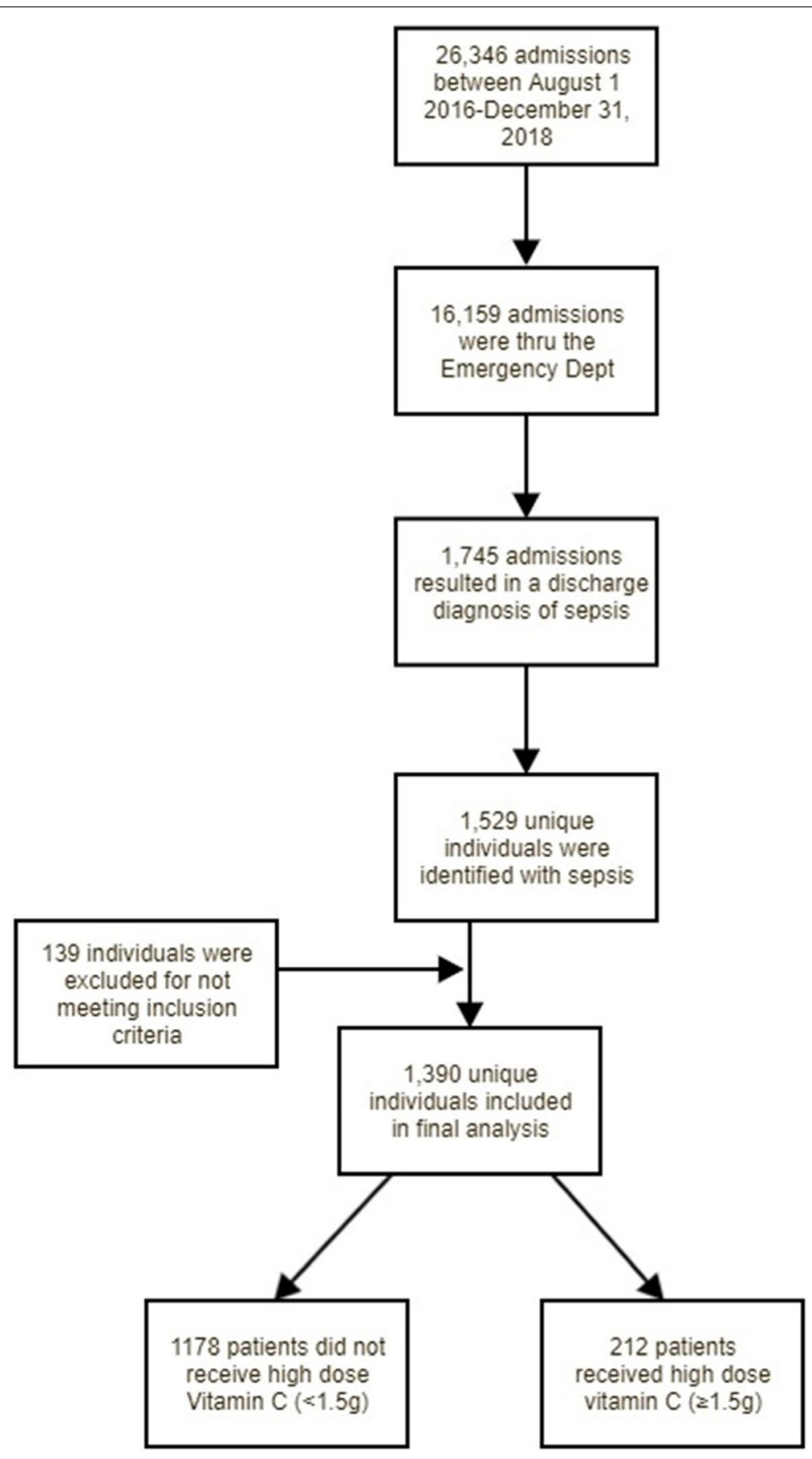

Fig. 1 Study Design

laboratory results, order sets ordered); primary and secondary diagnoses; hospital and ICU LOS; vasoactive drug use; and in-hospital mortality. Vasoactive drug use was defined as having received Dobutamine, Dopamine, Epinephrine, Norepinephrine, Phenylephrine, or Vasopressin. AKI was defined using ICD-10 code discharge diagnoses. Doses of IV vitamin C received were captured to categorize patients into two groups; comparison group (No or $<1.5 \mathrm{~g}$ of IV vitamin $\mathrm{C}$ ), and treatment group $(\geq 1.5 \mathrm{~g}$ of IV vitamin $\mathrm{C}$ within $12 \mathrm{~h}$ of hospital admission). Individuals who received $\geq 1.5 \mathrm{~g}$ of IV vitamin $\mathrm{C}$ more than $12 \mathrm{~h}$ after hospital admission were excluded 
from the study as research suggests that vitamin $C$ treatment after the first $12 \mathrm{~h}$ may not be as efficacious [30]. Similarly, patients who received a couple of doses after $12 \mathrm{~h}$ and remaining within the time frame were also excluded to obtain a uniform comparable study sample. Of note, two patients in the comparison group received low doses of IV vitamin C of $0.5 \mathrm{~g}$ or less (Fig. 1).

\section{Statistical analysis plan}

To assess bivariate associations, categorical data were compared using chi-square or Fisher's exact test when appropriate, and continuous data were analyzed using independent-samples t-tests. Preliminary analyses revealed statistically significant demographic differences between individuals in the treatment versus comparison groups (Table 1). Considering the retrospective nature of the study where the treatment was not randomly assigned, we used propensity score matching (PSM) to balance the covariate distribution between groups. Further, as our treated and untreated groups are not directly comparable because they may systematically differ at baseline, propensity score matching plays an important role in balancing the study groups to make them comparable. The variables that were matched and selected for various subgroups are: insurance, race, biological sex, history of diabetes, history of hypertension, vasoactive drug use, and patient age. Vasoactive drug use was included as a marker of illness severity. The greedy method for matching was performed using a 3:1 ratio (comparison: treatment) to best match the groups' sample size of the full study population. Utilizing the 3:1 ratio for matching the entire study population of sepsis patients meeting inclusion critiera (1390) was able to be used in the final analysis.

Using the matched sample, preliminary bivariate associations with primary outcome variables (i.e., AKI, mortality) were conducted and statistically significant and clinically meaningful variables were entered into two multiple logistic regressions. As the majority of patients (96\%) who received high dose IV vitamin C were admitted to the ICU, subsequent analyses were conducted on the sub-sample of ICU patients. Similar to the full population, PSM using the aforementioned variables was performed to balance between treatment and comparison groups who were seen in the ICU, with matching performed using a 2:1 ratio (comparison: treatment) to match the ICU groups' sample sizes. Preliminary bivariate analyses and multiple logistic regressions were then conducted on the ICU sample predicting AKI and mortality. A $p$-value of less than 0.05 and $95 \%$ confidence intervals $(\mathrm{CI})$ not including one were considered significant. All analyses were performed using SAS 9.4 software.
Table 1 Bivariate Analyses between IV Vitamin C Group and Comparison Group

\begin{tabular}{|c|c|c|c|}
\hline \multirow[b]{2}{*}{ Demographic Characteristic } & \multicolumn{2}{|c|}{ All Patients $(n=1390)$} & \multirow[b]{2}{*}{$\mathbf{p}$} \\
\hline & $\begin{array}{l}\text { IV vitamin C } \\
(n=212)\end{array}$ & $\begin{array}{l}\text { Comparison } \\
(n=1178)\end{array}$ & \\
\hline Continuous & $\mu \pm S E$ & $\mu \pm S E$ & \\
\hline Age (years) & $62 \pm 1.15$ & $59 \pm 0.51$ & 0.02 \\
\hline Length of Stay (hours) & $302 \pm 18$ & $319 \pm 13$ & 0.44 \\
\hline Length of Stay in ICU (hours) & $119 \pm 10$ & $76 \pm 6$ & $<0.001$ \\
\hline Categorical & n (\%) & n (\%) & $\mathrm{p}$ \\
\hline \multicolumn{4}{|l|}{ Insurance Status } \\
\hline Government & $182(86)$ & $893(76)$ & 0.001 \\
\hline Other & $30(14)$ & $285(24)$ & \\
\hline \multicolumn{4}{|l|}{ Race } \\
\hline Black & $118(56)$ & $611(52)$ & 0.57 \\
\hline White & $84(39)$ & $500(42)$ & \\
\hline Other/Unknown & $10(5)$ & $67(6)$ & \\
\hline \multicolumn{4}{|l|}{ Biological Sex } \\
\hline Female & $100(47)$ & $542(46)$ & 0.76 \\
\hline Male & $112(53)$ & $636(54)$ & \\
\hline \multicolumn{4}{|l|}{ Hypertension } \\
\hline Yes & $71(33)$ & 454 (39) & 0.16 \\
\hline No & $141(67)$ & $724(61)$ & \\
\hline \multicolumn{4}{|l|}{ Diabetes } \\
\hline Yes & $17(8)$ & $112(10)$ & 0.49 \\
\hline No & $195(92)$ & $1066(90)$ & \\
\hline \multicolumn{4}{|l|}{ Vasoactive Drug Use* } \\
\hline Yes & $36(17)$ & $193(16)$ & 0.83 \\
\hline No & 176 (83) & 985 (84) & \\
\hline \multicolumn{4}{|l|}{ AKI } \\
\hline Yes & $145(68)$ & $550(47)$ & $<0.001$ \\
\hline No & $67(32)$ & $628(53)$ & \\
\hline \multicolumn{4}{|l|}{ Death } \\
\hline Yes & $30(14)$ & 89 (8) & 0.002 \\
\hline No & $182(86)$ & $1089(92)$ & \\
\hline
\end{tabular}

AKI Acute Kidney Injury

*Vasoactive drug use was defined as having received at least one of the following: Dobutamine, Dopamine, Epinephrine, Norepinephrine, Phenylephrine, or Vasopressin

\section{Results}

Sample demographics and Descriptives

Of the 26,346 patient admissions between 1 August 2016 and 31 December 2018, 16,159 were admitted via the ED. Of the ED admissions, 1390 were identified as having a diagnosis of sepsis alone, based on 42 ICD-10 codes and were included for analysis. Overall, diagnosis of AKI and in-hospital mortality rates were 50 and $9 \%$, respectively. Patients were primarily male (54\%), identified as black $(52 \%)$ or white $(42 \%)$, and had an average age of 59 years. The majority of patients had government insurance 
(77\%), 38 and $9 \%$ of patients had a diagnosis of hypertension and diabetes, respectively, and $16 \%$ of patients received vasoactive drugs during their visit (see Table 2). Of the 1390 patients, 212 (15\%) were identified as part of the IV vitamin C treatment group and 1178 (85\%) were considered part of the comparison group. Within the treatment group, patients received high dose IV vitamin $\mathrm{C}$, on average, $4.58 \mathrm{~h}$ after admission.

Bivariate analyses revealed that individuals in the IV vitamin $C$ group were slightly older (61 years versus 58 years, $p=0.02)$, had longer ICU LOS $(119 \mathrm{~h}$ versus $76 \mathrm{~h}, p<0.001$ ), were less likely to have a history of

Table 2 Overall Descriptive Statistics ( $n=1390$ )

\begin{tabular}{|c|c|}
\hline Continuous Variables & $\boldsymbol{\mu} \pm \mathrm{SE}$ \\
\hline Age (years) & $59 \pm 0.46$ \\
\hline $\begin{array}{l}\text { Length of Stay (hours) } \\
\text { Length of Stay in ICU (hours) }\end{array}$ & $\begin{array}{l}316 \pm 11 \\
82 \pm 5\end{array}$ \\
\hline Categorical Variables & n (\%) \\
\hline \multicolumn{2}{|l|}{ Insurance Status } \\
\hline Government & 1075(77) \\
\hline Other & $315(23)$ \\
\hline \multicolumn{2}{|l|}{ Race } \\
\hline Black & $729(52)$ \\
\hline White & $584(42)$ \\
\hline Other/Unknown & $77(6)$ \\
\hline \multicolumn{2}{|l|}{ Biological Sex } \\
\hline Female & $642(46)$ \\
\hline Male & $748(54)$ \\
\hline \multicolumn{2}{|l|}{ Hypertension } \\
\hline Yes & $525(38)$ \\
\hline No & $865(62)$ \\
\hline \multicolumn{2}{|l|}{ Diabetes } \\
\hline Yes & 129(9) \\
\hline No & 1261(91) \\
\hline \multicolumn{2}{|l|}{ Vasoactive Drug Use* } \\
\hline Yes & $229(16)$ \\
\hline No & $1161(84)$ \\
\hline \multicolumn{2}{|l|}{ IV vitamin C Use } \\
\hline Yes & $212(15)$ \\
\hline No & 1178(85) \\
\hline \multicolumn{2}{|l|}{ AKI } \\
\hline Yes & $695(50)$ \\
\hline No & $695(50)$ \\
\hline \multicolumn{2}{|l|}{ Death } \\
\hline Yes & 119(9) \\
\hline No & $1271(91)$ \\
\hline
\end{tabular}

AKI Acute Kidney Injury

*Vasoactive drug use was defined as having received at least one of the following: Dobutamine, Dopamine, Epinephrine, Norepinephrine, Phenylephrine, or Vasopressin hypertension (33\% versus $39 \%, p=0.02)$, more likely to have AKI ( $68 \%$ versus $47 \%, p<0.001)$, and more likely to have died in the hospital ( $14 \%$ versus $8 \%, p=0.002$ ) compared to those in the comparison group (see Table 1). Given the differences between treatment and comparison groups, PSM was performed to balance covariates. The 3:1 matching reduced the full sample to $N=848$ and the ICU group 2:1 matching reduced the ICU sample to $N=534$. After PSM, preliminary analyses revealed that the treatment group was more likely to develop AKI (68\% versus $49 \%, p<0.001)$ and more likely to have died in the hospital (14.15\% versus $8.02 \%, p=0.01)$. Results of the multivariate logistic regressions are described below.

\section{Acute kidney injury}

A multivariate logistic regression determining adjusted odds ratio (AOR) revealed that age (AOR: 1.03 95\%CI: 1.02-1.04), ICU LOS (AOR: 1.003 95\%CI: 1.001-1.004), race (i.e., black compared to white; AOR: 1.59 95\%CI: 1.12-2.16), sex (i.e., female compared to male; AOR: 0.70 95\%CI: 0.52-0.93), and IV vitamin C (AOR: 2.07 95\%CI: 1.46-2.93) were associated with an increased likelihood of AKI. Other covariates including insurance, hypertension, diabetes, and vasoactive drug use were not significant. See Table 3a.

\section{Mortality}

A multivariate logistic regression predicting mortality revealed that age (AOR: 1.03 95\%CI: 1.007-1.05), ICU LOS (AOR: 1.002 95\% CI: 1.001-1.003), diagnosis of AKI (AOR: 3.21 95\%CI: 1.70-6.03), and IV vitamin C (AOR: 1.67 95\% CI: 1.003-2.78) were associated with in-hospital mortality. Insurance, race, hypertension, diabetes, and vasoactive drug use were not significant. See Table $3 \mathrm{~b}$.

\section{Sub-analysis on ICU patients only $(n=534)$ Acute kidney injury}

A multivariate logistic regression performed on the subset of individuals who spent time in the ICU found that age (AOR: 1.02 95\% CI: 1.01-1.04), ICU LOS (AOR: 1.003 95\% CI: 1.001-1.004), and IV vitamin C (AOR: 1.61 95\% CI: 1.09-2.39) were significant predictors of AKI. All other covariates were not significant. See Table 4a.

\section{Mortality}

A multivariate logistic regression revealed that age (AOR: 1.03 95\% CI: 1.01-1.04) and AKI (AOR: 2.01 95\% CI: 1.12-3.59) were significant predictors of in-hospital mortality. All other variables in the regression analysis, including IV vitamin $C$, were not significant. See Table $4 \mathrm{~b}$. 
Table 3 Multiple Logistic Regression Models Predicting Acute Kidney Injury and Mortality in the Total Population Performed after Propensity Score Matching (3:1) $(n=848)$

\begin{tabular}{|c|c|c|c|c|}
\hline \multicolumn{3}{|l|}{ a. Acute Kidney Injury } & \multicolumn{2}{|l|}{ b. Mortality } \\
\hline Variable & Adjusted-OR (95\% CI) & $p$-value & Adjusted-OR (95\% CI) & $p$-value \\
\hline Age (years) & $1.03(1.02,1.04)$ & $<0.001$ & $1.03(1.01,1.05)$ & 0.007 \\
\hline Length of ICU Stay (hours) & $1.003(1.001,1.004)$ & $<0.001$ & $1.002(1.001,1.003)$ & $<0.001$ \\
\hline Insurance (ref=Other) & $0.78(0.51,1.21)$ & 0.27 & $1.03(0.44,2.39)$ & 0.95 \\
\hline \multicolumn{5}{|l|}{ Race (ref=White) } \\
\hline Black & $1.59(1.18,2.16)$ & 0.04 & $1.31(0.78$ & 0.64 \\
\hline Other/Unknown & $1.14(0.58,2.24)$ & 0.76 & $\begin{array}{l}2.20) \\
2.28(0.83,6.29)\end{array}$ & 0.16 \\
\hline Biological Sex (ref= Male) & $0.70(0.52,0.93)$ & 0.01 & $0.80(0.48,1.32)$ & 0.38 \\
\hline Hypertension (ref=No) & $0.78(0.57,1.07)$ & 0.12 & $1.30(0.77,2.20)$ & 0.33 \\
\hline Diabetes $(\mathrm{ref}=\mathrm{No})$ & $0.85(0.50,1.45)$ & 0.55 & $0.87(0.33,2.33)$ & 0.78 \\
\hline Vasoactive Drug Use $($ ref $=$ No) & $1.54(0.98,2.40)$ & 0.06 & $1.46(0.81,2.63)$ & 0.21 \\
\hline IV vitamin C (ref $=$ No $)$ & $2.07(1.46,2.93)$ & $<0.001$ & $1.67(1.003,2.78)$ & 0.04 \\
\hline AKI & & & $3.21(1.70,6.03)$ & $<0.001$ \\
\hline
\end{tabular}

AKI Acute Kidney Injury

*Vasoactive drug use was defined as having received at least one of the following: Dobutamine, Dopamine, Epinephrine, Norepinephrine, Phenylephrine, or Vasopressin

Table 4 Multiple Logistic Regression Models Predicting Mortality and Acute Kidney Injury in the ICU Population Performed after Propensity Score Matching $(2: 1)(n=534)$

\begin{tabular}{|c|c|c|c|c|}
\hline \multicolumn{3}{|l|}{ a. Acute Kidney Injury } & \multicolumn{2}{|l|}{ b. Mortality } \\
\hline Variable & Adjusted-OR (95\% CI) & $p$-value & Adjusted-OR (95\% Cl) & $p$-value \\
\hline Age (years) & $1.02(1.01,1.04)$ & $<0.001$ & $1.03(1.007,1.04)$ & 0.01 \\
\hline Length of ICU Stay (hours) & $1.003(1.001,1.004)$ & $<.001$ & $1.001(1.000,1.002)$ & 0.05 \\
\hline Insurance (ref=Other) & $0.93(0.56,1.54)$ & 0.78 & $1.51(0.68,3.33)$ & 0.31 \\
\hline \multicolumn{5}{|l|}{ Race (ref = White) } \\
\hline Black & $1.47(0.99,2.19)$ & 0.04 & $1.56(0.94,2.60)$ & 0.85 \\
\hline Other/Unknown & $0.71(0.28,1.78)$ & 0.24 & $2.77(0.88,8.73)$ & 0.16 \\
\hline Biological Sex (ref=Male) & $0.77(0.52,1.12)$ & 0.17 & $0.67(0.41,1.11)$ & 0.12 \\
\hline Hypertension (ref=No) & $0.72(0.49,1.08)$ & 0.11 & $1.18(0.70,1.96)$ & 0.54 \\
\hline Diabetes $(r e f=$ No $)$ & $1.39(0.68,2.83)$ & 0.37 & $0.47(0.16,1.38)$ & 0.17 \\
\hline Vasoactive Drug Use $($ ref $=$ No) & $1.37(0.84,2.24)$ & 0.20 & $0.90(0.50,1.63)$ & 0.72 \\
\hline IV vitamin C (ref $=$ No $)$ & $1.61(1.09,2.39)$ & 0.02 & $0.79(0.48,1.31)$ & 0.36 \\
\hline AKI & & & $2.01(1.12,3.59)$ & 0.02 \\
\hline
\end{tabular}

AKI Acute Kidney Injury

*Vasoactive drug use was defined as having received at least one of the following: Dobutamine, Dopamine, Epinephrine, Norepinephrine, Phenylephrine, or Vasopressin

\section{Discussion}

This retrospective study of patients hospitalized for sepsis revealed an association between IV vitamin C usage and subsequent $\mathrm{AKI}$ and in-hospital mortality. When examining the association of IV vitamin C therapy and AKI, the odds of experiencing AKI for individuals treated with IV vitamin $C$ were $107 \%$ higher than the odds for individuals not treated with IV vitamin $\mathrm{C}$, after controlling for a number of demographic and clinical variables. Findings also revealed that risk of AKI was increased for those who were male and older, which is supported in previous research [31,32]. Findings are consistent with results from a similar study of patients admitted via the ED for sepsis, which found that individuals over 65 years were at significantly higher risk of AKI and subsequent in-hospital death [33]. Other research has also highlighted the 
relationships between increased LOS and older age, and the occurrence of AKI and mortality [34, 35]. Other notable factors in the current study associated with increased risk of AKI were longer ICU LOS and identifying as black as compared to white, both of which are risk factors supported by previous research [36-38]. The association between IV vitamin $\mathrm{C}$ and AKI is not unique to this study; a study by Litwak et al. observed a $12 \%$ increase in AKI in patients that received IV vitamin $C$ but this did not reach statistical significance, likely due to small sample size [22]. Additionally, this relationship between IV vitamin $C$ and AKI has been identified in several case reports [23-25]. The results from the current study differ from a large clinical trial (VICTAS) and a smaller retrospective study that found a beneficial relationship between IV vitamin $C$ and AKI. The disparate results may also be explained by sample size and related power; the VICTAS study was ended earlier than planned and the retrospective study had a small sample size of only 47 patients $[15,26]$.

When examining in-hospital mortality, results revealed that being older, having AKI, longer ICU LOS, and receiving IV vitamin $\mathrm{C}$ were associated with increased risk of mortality. Specifically, the odds of mortality were $67 \%$ higher for the IV vitamin C group compared to those in the comparison group. The association between high dose vitamin $C$ and death was unexpected and not easily explained. Another variable found to be associated with an increased risk of death, which may lend insight into the relationship between vitamin $\mathrm{C}$ and mortality, was the diagnosis of AKI. Previous research indicates kidney failure increases the risk of death six to eight times in septic patients [39]. However, when examining the data in the current study, an increased risk of death was evident irrespective of AKI. Among patients who did not have AKI and did not receive IV vitamin C, 3.03\% died compared to $7.46 \%$ of those who did not have AKI but received IV vitamin $C$. This suggests there may be a direct effect of high dose vitamin $C$ that may exacerbate the risk of mortality. The current study lacked the data that would allow for a more comprehensive examination between high doses of IV vitamin C and potential increased toxicity outside of the kidney, however, future research should explore the relationship between vitamin $\mathrm{C}$ and mortality, irrespective of AKI.

The current finding that IV vitamin $\mathrm{C}$ is associated with increased risk of death is inconsistent with another large retrospective study which found IV vitamin $C$ to be associated with reduced mortality among patients with sepsis [21]. One reason for the disparate results may be differences in treatment dose. Specifically, vitamin $C$ in the Byerly et al. study was not limited to high dose and was not defined by a threshold defining the treatment group, whereas the current study examines what is considered high dose IV vitamin $\mathrm{C}(\geq 1.5 \mathrm{~g})$, which may account for outcome differences. One study that examined higher doses $(200 \mathrm{mg} / \mathrm{kg} /$ day) of vitamin $\mathrm{C}$ showed evidence of increasing rates of mortality, with higher mortality (50.6\%) among a high dose vitamin $\mathrm{C}$ group compared to patients who received lower doses of vitamin C $(50 \mathrm{mg} /$ $\mathrm{kg} /$ day) (38\%), though both treatment groups had lower mortality than the placebo group (63\%) [14]. Notably, this study was limited by a small sample size and did not reach statistical significance. Additional research examining other clinical markers including SOFA scores in patients receiving high dose IV vitamin $C$ over long periods of time is needed.

Sub-analyses of the ICU sample revealed that age, longer ICU LOS, and receiving IV vitamin $\mathrm{C}$ remained predictors of AKI, while identifying as black and being male were no longer significant predictors. Older age, and ICU LOS are both known risk factors supported by previous research [36-38]. A second sub-analysis revealed that age and AKI remained significant predictors of inhospital mortality, however high dose IV vitamin $\mathrm{C}$ use was no longer a statistically significant predictor of mortality once the sample was limited to ICU patients only.

The current study observed a moderate relationship between IV vitamin $C$ and mortality in septic patients, which might suggest potential nephrotoxicity of vitamin $C$ therapy. The association between high dose vitamin $C$ and AKI due to oxalate deposition in renal tubules is well established [40]. Since early reports in 1985, there are multiple cases of AKI resulting from high dose vitamin C, administered parenterally or orally [23, 41-44]. Ascorbic acid is metabolized intracellularly and converted to oxalic acid [45]; the oxalic acid is then filtered in the kidney where it precipitates into crystals of calcium oxalate, potentially causing obstruction and tubular injury. Previous research has shown that vitamin $\mathrm{C}$ doses as low as $480-960 \mathrm{mg} / \mathrm{D}$, taken orally over several months, have resulted in oxalate deposition kidney failure that requires temporary dialysis [46]. Dietary supplementation of $2 \mathrm{~g}$ per day can increase oxalate excretion by $21.8 \%$ [47]. Oxalic acid and oxalate toxicity have been shown to occur in myocardial tissue of patients with hereditary hyperoxaluria [48]. Others have suggested that similar myocardial tissue damage can occur in secondary forms of hyperoxalosis $[49,50]$. Acutely elevated oxalate levels in the serum could cause myocardial dysfunction, leading to increased risk of mortality regardless of AKI.

\section{Limitations}

This study was limited in the retrospective nature of the design, which precludes causal-effect conclusions and prevents patient follow-up. Relatedly, the EHR data 
utilized did not include time stamps for diagnoses and treatment, thus temporal order is unknown. However, strict inclusion and exclusion criteria were applied in an effort to reduce selection bias and focus on communityacquired sepsis. Further, as vasoactive drug use and ICU admission were the only available surrogates for illness severity, these factors were considered in the PSM and sample stratification, respectively. Although the current study was limited to one hospital, the large sample size provided adequate power to detect statistically significant associations between patient-level demographic and clinical variables, and specifically, vitamin $C$ usage, AKI, and mortality. Additionally, existing literature has commonly reported SOFA scores, which were unable to be utilized in the current study due to inconsistencies in collection. Many studies have used SOFA scores as a representation of mortality risk, whereas in the current study, we were able to directly examine in-hospital mortality as a primary outcome. Additionally, the usage of serum lactic acid and procalcitonin levels were reviewed as a potential measure of disease severity but could not be included in analyses due to data missing not at random. In other words, these laboratory tests were not performed equally across all groups of patients. Finally, the current study did not assess for other nephrotoxic drugs that could be related to AKI, such as antimicrobials and radiologic contrast dye. Future research should include these as well as other factors to assess the unique relationship between IV vitamin $C$ and AKI.

\section{Conclusion}

Vitamin $\mathrm{C}$ is required for many biological functions including tissue repair, proper immune function, and healing. In sepsis patients, vitamin $\mathrm{C}$ levels are depleted thus IV vitamin $C$ therapy is proposed as a mechanism of sepsis treatment. This retrospective review of patients with sepsis revealed though that early use of high dose IV vitamin C may increase the likelihood of AKI and does not serve as a protective factor against mortality. The association of vitamin C with AKI, along with the association of AKI and mortality in patients admitted to the ICU, suggests that high doses of vitamin $\mathrm{C}$ may not be beneficial but toxic. This finding, coupled with results from multiple randomized controlled prospective studies of IV vitamin $C$ with mixed results, suggests that wide-spread use of high dose IV vitamin $C$ requires further assessment. Research examining whether there are significant differences in IV vitamin $C$ therapy toxicity among sub-group populations is necessary to further identify appropriate usage of IV Vitamin C therapy. These investigations should also include the different sources of sepsis related to hospital admissions, including those admitted through other routes than the emergency department. Additional research utilizing existing hospital data from across the nation and worldwide are needed to better understand the relationship between high dose IV vitamin $C$ therapy and subsequent outcomes as well as determine the toxic/effective dose.

\begin{abstract}
Abbreviations
AKI: Acute Kidney Injury; AOR: Adjusted Odds Ratio; Cl: Confidence Interval; ED: Emergency Department; EVMS: Eastern Virginia Medical School; GFR: Glomerular Filtration Rate; HER: Electronic Health Record; ICD: International Classification of Diseases; ICU: Intensive Care Unit; IV: 'Intra Venous; KDIGO: Kidney Disease Improvement Global Outcome; LOS: in hospital Length of Stay; MDRD: Modification of Diet in Renal Diseases; OR: Odds Ratio; PSM: Propensity Score Matching; SAS: Statistical Analysis System; SOFA: Sequential Organ Failure Score; VICTAS: Vitamin C, Thiamine, and Steroids in Sepsis; WI: Wisconsin.
\end{abstract}

\section{Acknowledgments}

None.

\section{Authors' contributions}

TM (Corresponding Author) developed the conception; design of the work; the acquisition; interpretation of data; drafted the work; and substantively revised it. BS assisted in development of the conception; design of the work; analysis, interpretation of data; drafted the work and substantively revised it. MS assisted in the drafting of the work and substantively revised it. SP assisted in the drafting of the work and substantively revised it. AT led the analysis; interpretation of data; drafted the work; and substantively revised it. SD assisted in developing the conception; design of the work; the acquisition; analysis; interpretation of data; have drafted the work and substantively revised it. Each author has approved the submitted version. Each author has agreed both to be personally accountable for the author's own contributions and to ensure that questions related to the accuracy or integrity of any part of the work, even ones in which the author was not personally involved, are appropriately investigated, resolved, and the resolution documented in the literature. The author(s) read and approved the final manuscript.

\section{Funding}

Funding to conduct this study was provided by an institutional grant from EVMS-Sentara Healthcare Analytics and Delivery Science Institute (HADSI).

\section{Availability of data and materials}

The data that support the findings of this study were obtained from Sentara Healthcare, and restrictions apply to the availability of these data, which were used under the Sentara Healthcare and EVMS-Sentara Healthcare Analytics and Delivery Science Institute agreement for this study. Sentara Healthcare will consider sharing this data upon request. The data are not publicly available because they contain information that could compromise the privacy of the research participants. Requests to review the data can be made to Dr. Sunita Dodani MD PhD, Director, EVMS-Sentara Healthcare Analytics and Delivery Science Institute, Eastern Virginia Medical School, Norfolk, Virginia. Email: dodanis@evms.edu.

\section{Declarations}

Ethics approval and consent to participate

This study was approved by the Eastern Virginia Medical School, Norfolk Virginia, USA Institutional Review Board and Human Subjects' Committee on 12 December 2019 (19-05-XX-0131). The study was exempted from a full committee review because only fully de-identified data was provided to the researchers. As all data analyzed was de-identified prior to transfer to the research group no participate consents were required by the EVMS Institutional Review Board. EVMS Human Subjects Institutional Review Board Approval letter available from the corresponding author and the EVMS IRB tillmanhj@evms.edu. 


\section{Consent for publication}

All data was de-identified prior to transfer to the research group for analysis. No individual data is presented. There are no images or videos of individual patients within this report. No consents for publications were required by the EVMS IRB.

\section{Competing interests}

The authors declare that they have no competing interests.

\begin{abstract}
Author details
${ }^{1}$ Division of Nephrology, Department of Internal Medicine, Eastern Virginia Medical School, 301 Riverview Ave, Suite 600, Norfolk, Virginia 23510, USA. 2EVMS-Sentara Healthcare Analytics and Delivery Science Institute, Eastern Virginia Medical School, Norfolk, Virginia, USA. ${ }^{3}$ Department of Internal Medicine, Eastern Virginia Medical School, Norfolk, Virginia, USA. ${ }^{4}$ Department of Psychiatry and Behavioral Sciences, Eastern Virginia Medical School, Norfolk, Virginia, USA. ${ }^{5}$ Eastern Virginia Medical School, Norfolk, Virginia, USA. ${ }^{6}$ Division of Cardiology, Department of Internal Medicine, Eastern Virginia Medical School, Norfolk, Virginia, USA
\end{abstract}

Received: 27 June 2021 Accepted: 3 November 2021

Published online: 20 November 2021

\section{References}

1. Pauling $L$. The significance of the evidence about ascorbic acid and the common cold. Proc Natl Acad Sci U S A. 1971;68:2678-81. https://doi.org/ 10.1073/pnas.68.11.2678.

2. Frei B, Stocker R, England L, Ames BN. Ascorbate: the most effective antioxidant in human blood plasma. Adv Exp Med Biol. 1990;264:155-63. https://doi.org/10.1007/978-1-4684-5730-8_24.

3. Oudemans-van Straaten HM, Elbers PWG, Spoelstra-de Man AME. How to give vitamin C a cautious but fair chance in severe Sepsis. Chest. 2017:151:1199-200. https://doi.org/10.1016/j.chest.2017.01.008.

4. Berger MM, Oudemans-van Straaten HM. Vitamin C supplementation in the critically ill patient. Curr Opin Clin Nutr Metab Care. 2015;18:193-201. https://doi.org/10.1097/MCO.0000000000000148.

5. Schorah CJ, Downing C, Piripitsi A, Gallivan L, Al-Hazaa AH, Sanderson MJ, et al. Total vitamin C, ascorbic acid, and dehydroascorbic acid concentrations in plasma of critically ill patients. Am J Clin Nutr. 1996;63:760-5. https://doi.org/10.1093/ajcn/63.5.760.

6. Spoelstra-de Man AME, Oudemans-van Straaten HM, Berger MM. Adjuvant vitamin C for sepsis: mono or triple? Crit Care. 2019;23:425. https:// doi.org/10.1186/s13054-019-2717-x.

7. Heron M. Deaths: leading causes for 2017. Natl Vital Stat Rep. 2019;68:1-77

8. Rhee C, Dantes R, Epstein L, Murphy DJ, Seymour CW, Iwashyna TJ, et al. Incidence and trends of Sepsis in US hospitals using clinical vs claims data, 2009-2014. JAMA. 2017:318:1241-9. https://doi.org/10.1001/jama. 2017.13836.

9. Paoli CJ, Reynolds MA, Sinha M, Gitlin M, Crouser E. Epidemiology and costs of Sepsis in the United States-an analysis based on timing of diagnosis and severity level. Crit Care Med. 2018;46:1889-97. https://doi.org/ 10.1097/CCM.0000000000003342.

10. Rhee C, Jones TM, Hamad Y, Pande A, Varon J, O'Brien C, et al. Centers for disease $C$, prevention prevention epicenters $P$ : prevalence, underlying causes, and preventability of Sepsis-associated mortality in US acute care hospitals. JAMA Netw Open. 2019;2:e187571. https://doi.org/10.1001/ jamanetworkopen.2018.7571.

11. Abe T, Ogura H, Kushimoto S, Shiraishi A, Sugiyama T, Deshpande GA Uchida M, Nagata I, Saitoh D, Fujishima S, Mayumi T, Hifumi T, Shiino Y, Nakada TA, Tarui T, Otomo Y, Okamoto K, Umemura Y, Kotani J, Sakamoto Y, Sasaki J, Shiraishi SI, Takuma K, Tsuruta R, Hagiwara A, Yamakawa K, Masuno T, Takeyama N, Yamashita N, Ikeda H, Ueyama M, Fujimi S, Gando S, group JF: Variations in infection sites and mortality rates among patients in intensive care units with severe sepsis and septic shock in Japan. J Intensive Care, 7: 28, 2019 https://doi.org/10.1186/ s40560-019-0383-3

12. Korosec Jagodic H, Jagodic K, Podbregar M. Long-term outcome and quality of life of patients treated in surgical intensive care: a comparison between sepsis and trauma. Crit Care. 2006;10:R134. https://doi.org/10. $1186 /$ cc5047.

13. Mohamed AKS, Mehta AA, James P. Predictors of mortality of severe sepsis among adult patients in the medical intensive care unit. Lung India. 2017;34:330-5. https://doi.org/10.4103/lungindia.lungindia_54_16.

14. Fowler III AA, Syed AA, Knowlson S, Sculthorpe R, Farthing D, DeWilde C, Farthing CA, Larus TL, Martin E, Brophy DF, Gupta S, Medical Respiratory Intensive Care Unit N, Fisher BJ, Natarajan R: Phase I safety trial of intravenous ascorbic acid in patients with severe sepsis. J Transl Med, 12: 32, 2014 https://doi.org/10.1186/1479-5876-12-32

15. Marik PE, Khangoora V, Rivera R, Hooper MH, Catravas J. Hydrocortisone, vitamin $C$, and thiamine for the treatment of severe Sepsis and septic Shock: a retrospective before-after study. Chest. 2017;151:1229-38. https://doi.org/10.1016/j.chest.2016.11.036.

16. Chang P, Liao Y, Guan J, Guo Y, Zhao M, Hu J, et al. Combined treatment with hydrocortisone, vitamin C, and thiamine for Sepsis and septic Shock: a randomized controlled trial. Chest. 2020;158:174-82. https://doi.org/10. 1016/j.chest.2020.02.065.

17. Fowler III AA, Truwit JD, Hite RD, Morris PE, DeWilde C, Priday A, Fisher B, Thacker LR, 2nd, Natarajan R, Brophy DF, Sculthorpe R, Nanchal R, Syed A, Sturgill J, Martin GS, Sevransky J, Kashiouris M, Hamman S, Egan KF, Hastings A, Spencer W, Tench S, Mehkri O, Bindas J, Duggal A, Graf J, Zellner S, Yanny L, McPolin C, Hollrith T, Kramer D, Ojielo C, Damm T, Cassity E, Wieliczko A, Halquist M: Effect of Vitamin C Infusion on Organ Failure and Biomarkers of Inflammation and Vascular Injury in Patients With Sepsis and Severe Acute Respiratory Failure: The CITRIS-ALI Randomized Clinical Trial. JAMA, 322: 1261-1270, 2019 https://doi.org/10.1001/jama.2019. 11825

18. Fujii T, Luethi N, Young PJ, Frei DR, Eastwood GM, French CJ, Deane AM, Shehabi Y, Hajjar LA, Oliveira G, Udy AA, Orford N, Edney SJ, Hunt AL, Judd HL, Bitker L, Cioccari L, Naorungroj T, Yanase F, Bates S, McGain F, Hudson EP, Al-Bassam W, Dwivedi DB, Peppin C, McCracken P, Orosz J, Bailey M, Bellomo R, Investigators VT: Effect of Vitamin C, Hydrocortisone, and Thiamine vs Hydrocortisone Alone on Time Alive and Free of Vasopressor Support Among Patients With Septic Shock: The VITAMINS Randomized Clinical Trial. JAMA, 323: 423-431, 2020 https://doi.org/10.1001/jama. 2019.22176

19. Hwang SY, Ryoo SM, Park JE, Jo YH, Jang DH, Suh GJ, et al. Combination therapy of vitamin $C$ and thiamine for septic shock: a multi-Centre, double-blinded randomized, controlled study. Intensive Care Med. 2020. https://doi.org/10.1007/s00134-020-06191-3.

20. Moskowitz A, Huang DT, Hou PC, Gong J, Doshi PB, Grossestreuer AV, et al Effect of ascorbic acid, corticosteroids, and thiamine on organ injury in septic Shock: the ACTS randomized clinical trial. JAMA. 2020;324:642-50. https://doi.org/10.1001/jama.2020.11946.

21. Byerly S, Parreco JP, Soe-Lin H, Parks JJ, Lee EE, Shnaydman I, et al. Vitamin $\mathrm{C}$ and thiamine are associated with lower mortality in sepsis. J Trauma Acute Care Surg. 2020;89:111-7. https://doi.org/10.1097/TA.0000000000 002613.

22. Litwak JJ. Cho N, Nguyen HB, Moussavi K, Bushell T: vitamin C, hydrocortisone, and thiamine for the treatment of severe Sepsis and septic Shock: a retrospective analysis of real-world application. J Clin Med. 2019;8. https://doi.org/10.3390/jcm8040478.

23. McHugh GJ, Graber ML, Freebairn RC. Fatal vitamin C-associated acute renal failure. Anaesth Intensive Care. 2008;36:585-8. https://doi.org/10. 1177/0310057X0803600413.

24. Andres A, Zeier M, Eckert C. Acute kidney injury following high-dose vitamin C treatment. Dtsch Arztebl Int. 2019;116:756. https://doi.org/10 3238/arztebl.2019.0756.

25. Wissanji T, Dupuis ME, Royal V, Pichette V, Wang HT. Vitamin C-induced oxalate nephropathy in a septic patient. Crit Care Explor. 2021;3:e0389. https://doi.org/10.1097/CCE.0000000000000389.

26. Sevransky JE, Rothman RE, Hager DN, Bernard GR, Brown SM, Buchman TG, Busse LW, Coopersmith CM, DeWilde C, Ely EW, Eyzaguirre LM, Fowler AA, Gaieski DF, Gong MN, Hall A, Hinson JS, Hooper MH, Kelen GD, Khan A, Levine MA, Lewis RJ, Lindsell CJ, Marlin JS, McGlothlin A, Moore BL, Nugent KL, Nwosu S, Polito CC, Rice TW, Ricketts EP, Rudolph CC, Sanfilippo F, Viele K, Martin GS, Wright DW, Investigators V: Effect of Vitamin C, Thiamine, and Hydrocortisone on Ventilator- and Vasopressor-Free Days in Patients With Sepsis: The VICTAS Randomized Clinical Trial. JAMA, 325: 742-750, 2021 https://doi.org/10.1001/jama.2020.24505 
27. Putzu A, Daems AM, Lopez-Delgado JC, Giordano VF, Landoni G. The effect of vitamin C on clinical outcome in critically ill patients: a systematic review with Meta-analysis of randomized controlled trials. Crit Care Med. 2019;47:774-83. https://doi.org/10.1097/CCM.0000000000003700

28. Long MT, Kory P, Marik P. Vitamin C, hydrocortisone, and thiamine for septic Shock. JAMA. 2020;323:2203-4. https://doi.org/10.1001/jama.2020. 5844.

29. Levey AS, Coresh J, Greene T, Stevens LA, Zhang YL, Hendriksen S, Kusek JW, Van Lente F, Chronic Kidney Disease Epidemiology C: Using standardized serum creatinine values in the modification of diet in renal disease study equation for estimating glomerular filtration rate. Ann Intern Med, 145: 247-254, 2006 https://doi.org/10.7326/0003-4819-145-4-20060 8150-00004

30. Long MT, Frommelt MA, Ries MP, Murray M, Osman F, Krause BM, et al. Early hydrocortisone, ascorbate and thiamine therapy for severe septic shock. Critical Care and Shock. 2020;23:23-34.

31. Kane-Gill SL, Sileanu FE, Murugan R, Trietley GS, Handler SM, Kellum JA. Risk factors for acute kidney injury in older adults with critical illness: a retrospective cohort study. Am J Kidney Dis. 2015;65:860-9. https://doi. org/10.1053/j.ajkd.2014.10.018.

32. Neugarten J, Golestaneh L, Kolhe NV. Sex differences in acute kidney injury requiring dialysis. BMC Nephrol. 2018;19:131. https://doi.org/10. 1186/s12882-018-0937-y.

33. Medeiros P, Nga HS, Menezes P, Bridi R, Balbi A, Ponce D. Acute kidney injury in septic patients admitted to emergency clinical room: risk factors and outcome. Clin Exp Nephrol. 2015;19:859-66. https://doi.org/10.1007/ s10157-014-1076-9.

34. Wang HE, Muntner P, Chertow GM, Warnock DG. Acute kidney injury and mortality in hospitalized patients. Am J Nephrol. 2012;35:349-55. https:// doi.org/10.1159/000337487.

35. Yang Y, Yang KS, Hsann YM, Lim V, Ong BC. The effect of comorbidity and age on hospital mortality and length of stay in patients with sepsis. J Crit Care. 2010;25:398-405. https://doi.org/10.1016/j.jcrc.2009.09.001.

36. DiMeglio M, Dubensky J, Schadt S, Potdar R, Laudanski K. Factors underlying racial disparities in Sepsis management. Healthcare (Basel). 2018;6. https://doi.org/10.3390/healthcare6040133.

37. Grams ME, Matsushita K, Sang Y, Estrella MM, Foster MC, Tin A, et al. Explaining the racial difference in AKI incidence. J Am Soc Nephrol. 2014;25:1834-41. https://doi.org/10.1681/ASN.2013080867.

38. Hoste EA, Lameire NH, Vanholder RC, Benoit DD, Decruyenaere JM, Colardyn FA. Acute renal failure in patients with sepsis in a surgical ICU: predictive factors, incidence, comorbidity, and outcome. J Am Soc Nephrol. 2003;14:1022-30. https://doi.org/10.1097/01.asn.0000059863.48590. e9.
39. Gomez H, Kellum JA. Sepsis-induced acute kidney injury. Curr Opin Crit Care. 2016;22:546-53. https://doi.org/10.1097/MCC.0000000000000356

40. Hellman L, Burns JJ. Metabolism of L-ascorbic acid-1-C14 in man. J Biol Chem. 1958;230:923-30.

41. Gurm H, Sheta MA, Nivera N, Tunkel A. Vitamin C-induced oxalate nephropathy: a case report. J Community Hosp Intern Med Perspect. 2012;2. https://doi.org/10.3402/jchimp.v2i2.17718.

42. Lin WV, Turin CG, McCormick DW, Haas C, Constantine G. Ascorbic acidinduced oxalate nephropathy: a case report and discussion of pathologic mechanisms. CEN Case Rep. 2019;8:67-70. https://doi.org/10.1007/ s13730-018-0366-6.

43. Lawton JM, Conway LT, Crosson JT, Smith CL, Abraham PA. Acute oxalate nephropathy after massive ascorbic acid administration. Arch Intern Med. 1985;145:950-1.

44. Buehner M, Pamplin J, Studer L, Hughes RL, King BT, Graybill JC, et al. Oxalate nephropathy after continuous infusion of high-dose vitamin C as an adjunct to burn resuscitation. J Burn Care Res. 2016;37:e374-9. https:// doi.org/10.1097/BCR.0000000000000233.

45. Knight J, Madduma-Liyanage K, Mobley JA, Assimos DG, Holmes RP. Ascorbic acid intake and oxalate synthesis. Urolithiasis. 2016;44:289-97. https://doi.org/10.1007/s00240-016-0868-7.

46. Lamarche J, Nair R, Peguero A, Courville C. Vitamin C-induced oxalate nephropathy. Int J Nephrol. 2011;2011:146927. https://doi.org/10.4061/ 2011/146927.

47. Traxer O, Huet B, Poindexter J, Pak CY, Pearle MS. Effect of ascorbic acid consumption on urinary stone risk factors. J Urol. 2003;170:397-401. https://doi.org/10.1097/01.ju.0000076001.21606.53.

48. Mookadam F, Smith T, Jiamsripong P, Moustafa SE, Monico CG, Lieske JC, et al. Cardiac abnormalities in primary hyperoxaluria. Circ J. 2010;74:24039. https://doi.org/10.1253/circj.cj-10-0107.

49. Chaplin AJ. Histopathological occurrence and characterisation of calcium oxalate: a review. J Clin Pathol. 1977;30:800-11. https://doi.org/10.1136/ jcp.30.9.800.

50. Lorenz EC, Michet CJ, Milliner DS, Lieske JC. Update on oxalate crystal disease. Curr Rheumatol Rep. 2013;15:340. https://doi.org/10.1007/ s11926-013-0340-4.

\section{Publisher's Note}

Springer Nature remains neutral with regard to jurisdictional claims in published maps and institutional affiliations.
Ready to submit your research? Choose BMC and benefit from:

- fast, convenient online submission

- thorough peer review by experienced researchers in your field

- rapid publication on acceptance

- support for research data, including large and complex data types

- gold Open Access which fosters wider collaboration and increased citations

- maximum visibility for your research: over 100M website views per year

At BMC, research is always in progress.

Learn more biomedcentral.com/submissions 